\title{
Parametric Analysis for Varying Packing Materials \& Water Temperatures in a Humidifier
}

\author{
Sampath Suranjan Salins ${ }^{1}$, Shahida A Siddiqui ${ }^{2}$, S.V. Kota Reddy ${ }^{3}$, Shiva Kumar ${ }^{4}$ \\ ${ }^{1}$ Manipal Academy of higher education \\ DIAC, Dubai, United Arab Emirates PO 345050 \\ sampath@manipal.edu. \\ ${ }^{2}$ NRW, Germany, PO 45141 \\ shahidasiddiqui777@gmail.com \\ ${ }^{3}$ Manipal Academy of higher education \\ DIAC, Dubai, United Arab Emirates PO 345050 \\ svk_reddy@manipaldubai.com \\ ${ }^{4}$ Manipal Institute of technology, Manipal \\ Karnataka, India, PO 574104. \\ shiva.kumar@manipal.edu
}

\begin{abstract}
Consumption of energy by humans led to environmental problems like global warming and change in climate. Cooling of buildings is a main reason for the consumption of the energy in hot regions. The cooling system depends on the intensity of the sunshine in hot regions and a design of alternative means to minimize the energy consumption is utmost important. The present study, a comprehensive experimental parametric study is carried out for a new evaporative cooling pad made of coconut fibers. Fibers are arranged in the mesh to form a rigid element. The tests are carried out in a cross flow set up with evaporative cooling system by varying the air velocities as well as water temperatures. Performance parameters such as evaporation rate, pressure drop, specific cooling capacity, humidification efficiency, air temperature drop, and humidity rise are evaluated. The results are compared with the standard cooling pad material that is Cellulose or Celdek Packing. Results indicated that there is a rise in the coefficient of performance, cooling effect, humidification efficiency and evaporation rate with the air velocity. For the lower water temperature, the output parameters yielded highest value. The system yielded the humidification efficiency of $82 \%$ and the value of coefficient of performance obtained is 4.68.
\end{abstract}

Keywords: Coconut coir, Humidification efficiency, Evaporation rate, COP, Specific cooling capacity, Evaporative cooling pads.

\section{Introduction}

Evaporative cooling process involves in cooling of air with the evaporation of water. It is one of the oldest principles known and used in household cooling. It has less initial and operational cost compared to cooling by refrigeration. Evaporative coolers consist of water reservoir, pump, spray nozzles and the cooling pads. The water sprayed on pads, wet the surface, and comes in contact with the air stream. Evaporation process removes latent heat from the air stream and provides cooling effect at the outlet. Cooling by vapor compression refrigeration produce harmful effects to atmosphere and consumes substantial power. To overcome this problem, evaporative cooling phenomenon is effective to provide thermal comfort [1]. Cooling pads are affected by factors such as surface area, type of material, thickness, perforation size, flow rate, water volume and relative humidity of air passing through pad. Cooling pads are made of materials such as metal, wood, plastic, glass etc. and the manufacturing process is complex and expensive. Results showed that with the drop in the consumption of the power by 10 to $30 \%$, there is an increase in the COP of the overall system by 10 to $50 \%$. Few studies showed the utilization of various cooling pad materials which plays a substitute to the standard materials. Some of the materials are wood shaving, aspen, palash fibers etc. Pads made up of cellulose papers are economical, compact, lightweight, pollution free and durable. It is widely used in the applications such as residential buildings, green houses, swine house, poultry etc. [2]. To reduce electrical consumption, evaporative coolers are integrated with the VCR cycle, overall 
performance can be improved by evaporative precooling which drops the temperature of air before passing on to the evaporative coils. Evaporative cooling system is classified as direct, indirect, and indirect direct evaporative cooling. For the hot and dry climate direct evaporative cooling is suited. In direct evaporative cooling, warm air in the surrounding is sucked inside the unit to utilize the heat energy in evaporation of water molecules from the surface of pads. The temperature of the outlet air is reduced and increases the humidity of the environment. Indirect type does not improve the humidity, but it increases the cooling. It makes use of additional air source that is heated before it reaches the cooling pads. This generates cooler air [3]. The current topic discusses direct evaporative cooling mechanism and coconut coir as the cooling pad material selected in this study. Various authors have conducted the investigations related to evaporative coolers, using different resources selected as the pad materials.

Doğramacı et al. [4] used eucalyptus fiber pads to carry out evaporative cooling. A wind tunnel is used to investigate the performance of the fibers. Results indicated that the maximum reduction in the temperature, increase in the humidity and the cooling performance was found to be $11.3^{\circ} \mathrm{C}, 71 \%$ and 409 Watts, respectively. Laknizi et al. [5] optimized various thermodynamic properties of humid air using a computer program Cool prop. Program was used to relate frontal velocity and the thickness of the pad. System used cellulose packing and results indicated that during summer season, maximum cooling is obtained with high COP and the water consumption is higher than $3.3 \mathrm{~kg} / \mathrm{hr}$. Dhamneya.[6] used aspen pads and studied different configuration of cooling pads to understand the behaviour pattern of direct evaporative cooling. Results indicated that highest saturation efficiency is found for triangle configuration. Xu et al. [7] developed a compact humidifier with novel ceramic foam packing. Packing dimensions were calculated by analytical method based on Merkel theory. Experimentation was carried out and it is found that there was an improvement in humidification by $11 \%$. Rafique et al. [8] used desiccant based evaporative coolers and its configuration. This work concludes that the evaporative cooling technology provides better thermal comfort than the conventional cooling systems. Camargo [9] developed a mathematical model which gives the correlation between the fluids where the thermal exchange takes place. Results obtained by the mathematical model were compared with the experimental evaporative cooling. Franco A. et al. [10] used low speed wind tunnel for conducting the experiments on four pads with variable thickness. The pressure drop obtained in the plastic type pad was less than that of cellulose pads. Results indicated that system gave a saturation efficiency of $82.63 \%$. Kabeel et al. [11] worked on cellulose packing with varying configuration in humidification dehumidification system. Solar water heater was integrated with the desalination unit. Results indicated that there was a productivity of $23.6 \mathrm{~kg} / \mathrm{hr}$. Shahali et al. [12] investigated the wet cool tower performance with the experimentation. Different packing ribs were studied and its influence in humidification is studied. Results indicated that experimental results matched with the mathematic equations derived from regression analysis. Martínez. et al. [13] experimented on evaporative cooling system with three different pad size, 80, 16- and 250-mm thickness. Air velocity, water flow rate and thickness of pad varied. Results indicated that the system gave saturation efficiency of $80.5 \%$ and the pressure drop obtained is $17 \mathrm{~Pa}$. Liu X.et al. [14] built a cross flow packed dehumidification system to investigate the filtration efficiency water and air are used as fluids. Results indicated there is a rise in humidification performance. Li. et al. [15] constructed a humidification dehumidification system to obtain optimum humidification parameters. A mathematical model was constructed to predict the experimental results. It was found out that numerical and experimental results were matching. Warke D.A. and Deshmukh [16] used two cooling pads (5090 and 7090) made of corrugated paper. It was investigated in subsonic wind tunnel. Investigation of humidification was carried out for three different thickness pads and materials. Results indicated that increase in thickness improved the humidification and cellulose pads gave maximum performance compared to Aspen and Khus pads. Sharma et al. [17] worked towards humidification and cooling with the use of Peltier module device. Al-Sulaiman [18] analyzed various materials like date palm fibers and luffa for the evaporative cooling pad. Luffa pads gave cooling efficiency percentage of $55.1 \%$ whereas date palm gave a less efficiency of $38.9 \%$.

From the detailed study of the literature, following research gaps are identified. Naturally occurring fibers are not much utilized as evaporative cooling pads. In addition to cooling of air, controlling the relative humidity and maintaining the required temperature of the air is one of the important aspects of thermal comfort. This can be done with integrating the normal VCR cycle with evaporative cooling technique. Integration of the vapor compression refrigeration together 
with the evaporative cooling has not been investigated by the researchers. From the research gaps obtained, the following objectives have been set. To investigate experimentally the performance of coconut coir as the evaporating pad material by comparing with the Celdek packing. Integration of the humidification test rig with the vapor compression refrigeration cycle to improve the cooling effect and the temperature drop.

\section{Methodology:}

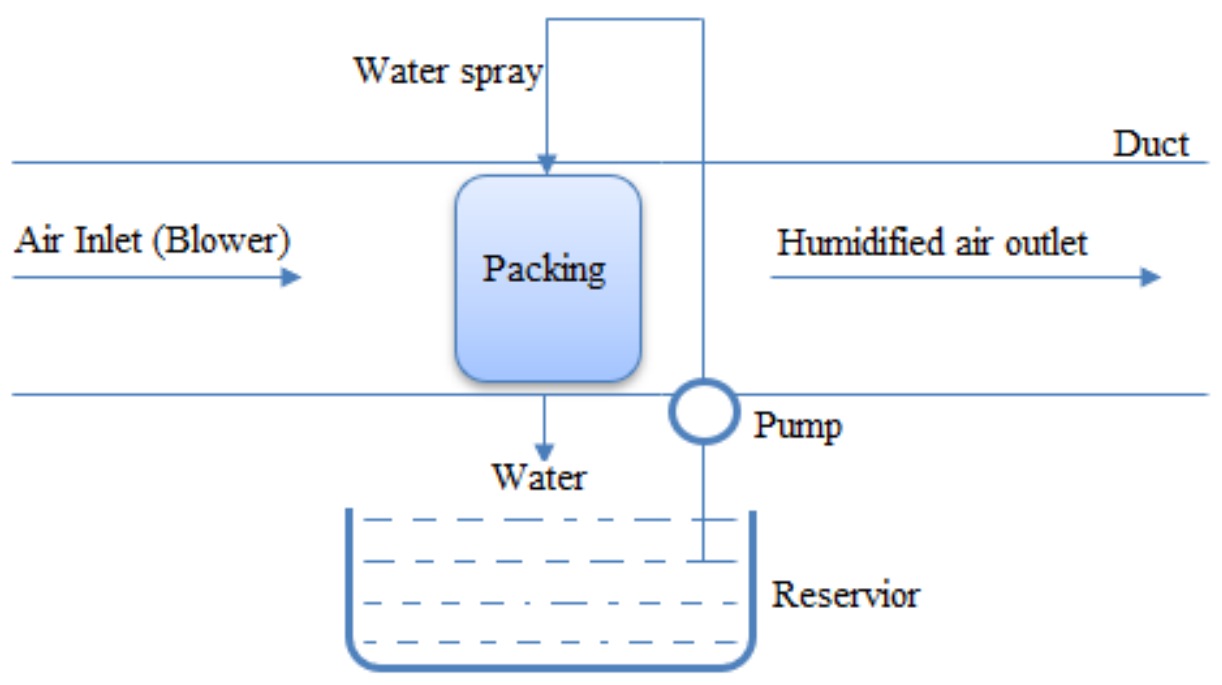

Fig.1: Principle of humidification.

Evaporative cooling is the main principle used in the process of humidification. Figure. 1 shows the principle of humidification where air at known velocity is blown into the duct and it interacts with the cooling pads which get soaked when water sprayed on it. Inlet conditions like variation in the air velocity, water temperature and cooling pad material will yield the different output parameters. Following governing equations are used to predict the output parameters of humidification. Water Evaporation rate is defined as the total amount of moisture getting evaporated it is product of mass flow rate of air and the difference in specific humidity. It is given by equation (1)

$$
m_{w}=m_{a}\left(w_{2}-w_{1}\right)
$$

Saturation efficiency shown in equation (2) shows the humidity percentage addition to the regular input air. It is defined as the ratio of the temperature difference between inlet and outlet dry bulb temperatures to the difference between the inlet dry bulb and wet bulb temperatures.

$$
\eta_{\text {Humidification }}=\frac{\left(T_{1 d}-T_{2 d}\right)}{\left(T_{1 d}-T_{1 w}\right)}
$$

$\mathrm{COP}$ refers to the ratio of output cooling effect to the input work done by the blower, pump and refrigeration cycle. Equation (3) shows the calculation of COP.

$$
C O P=\frac{Q_{C}}{\left(W_{\text {Pump }}+W_{\text {Fan }}+W_{\text {Ref }}\right)}
$$

The specific cooling capacity (SCC) shown in equation (4) is used to find the cooling capacity obtained per kg of water evaporated. It is the ratio of cooling capacity (CC) to evaporation rate (ER). Equation (6) represents the specific cooling capacity 
$\mathrm{SCC}=$ Cooling capacity/ Evaporation rate

$$
S C C=\frac{Q}{m_{w}}=\frac{m_{a} C_{p} \Delta t}{m_{a}\left(w_{2}-w_{1}\right)}
$$

\section{Experimental Setup and Measuring devices:}

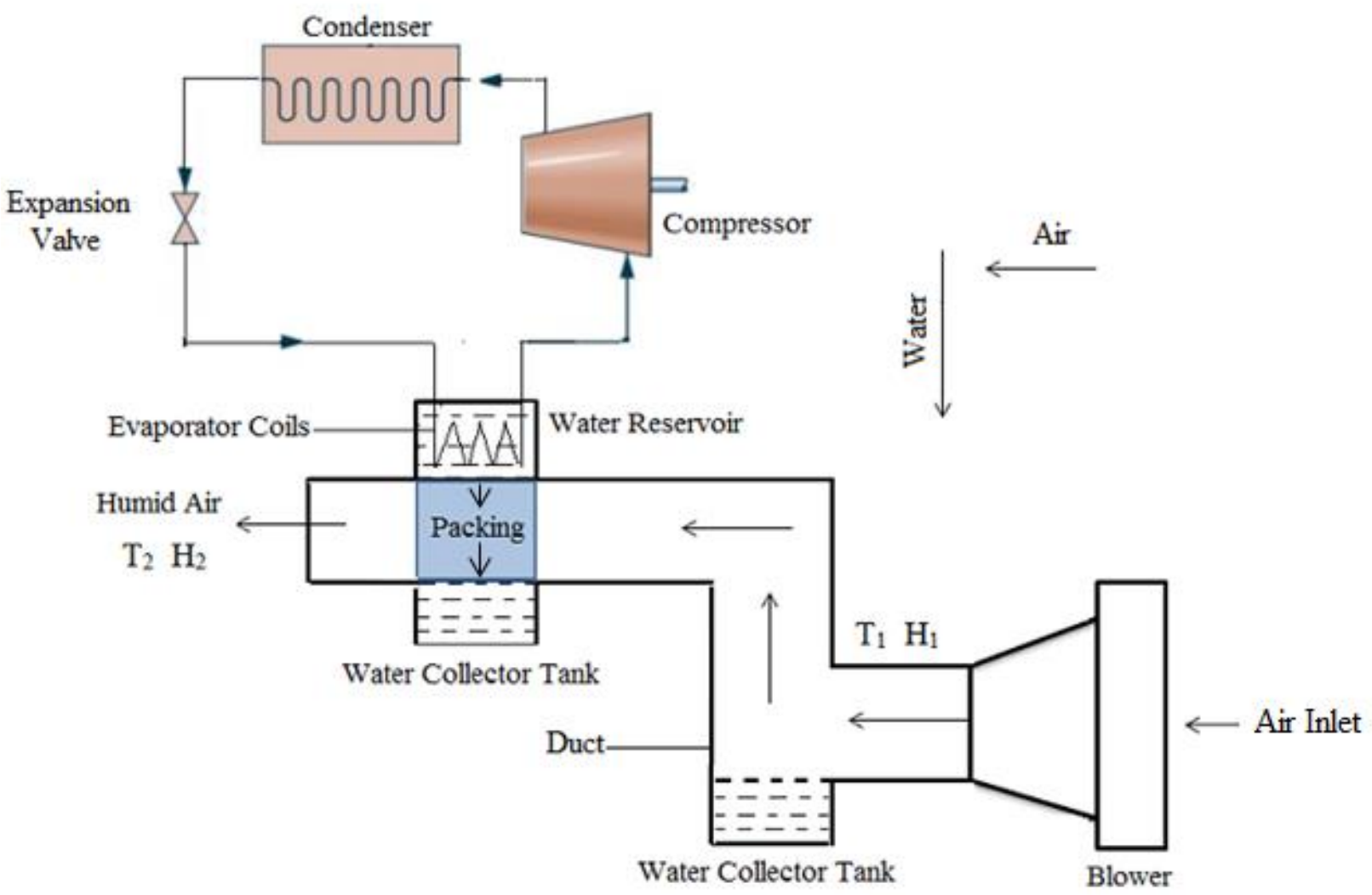

Fig. 2: Experimental set up for cross flow humidification.

Figure 2 shows the schematic sketch of cross flow humidification system. It basically consists of duct, where air is circulated from the blower with capacity of 0.25 horsepower at variable velocities. A packing or cooling pad element which has the wettability property to hold the moisture is used to augment humidification. Coconut coir fibers are filled in a mesh which act like a packing. Pump with the capacity of 0.1 horsepower is used to fill the water reservoir and the water is made to drip on the packing by gravity. Water temperature is controlled by vapor compression cycle, the evaporator coils are dipped in the water. When air blows on the packing, there is a surface contact taking place between packing and air, where it will carry the moisture along with it. The outlet air is humidified. The excess water collects in the water collector tank. In cross flow fluids interact in perpendicular direction. Various inlet parameters such as air velocity, water temperature, air temperature and relative humidity at the inlet are noted down. Similarly, these parameters at the outlet are also monitored. Then performance parameters such as coefficient of performance, specific cooling capacity, evaporation rate, humidification efficiency and cooling effect are calculated using the equations as mentioned from equations 1 - 4 . 
Celdek packing and coconut packing are shown in the figures 3 and 4 respectively are inserted into a frame made of Mild steel. Pad materials have been chosen in such a way that they exactly fit inside the frame structure as shown in figure 5. In case of Celdek packing, the total wettability obtained for the selected packing is $632 \mathrm{~m}^{2} / \mathrm{m}^{3}$.

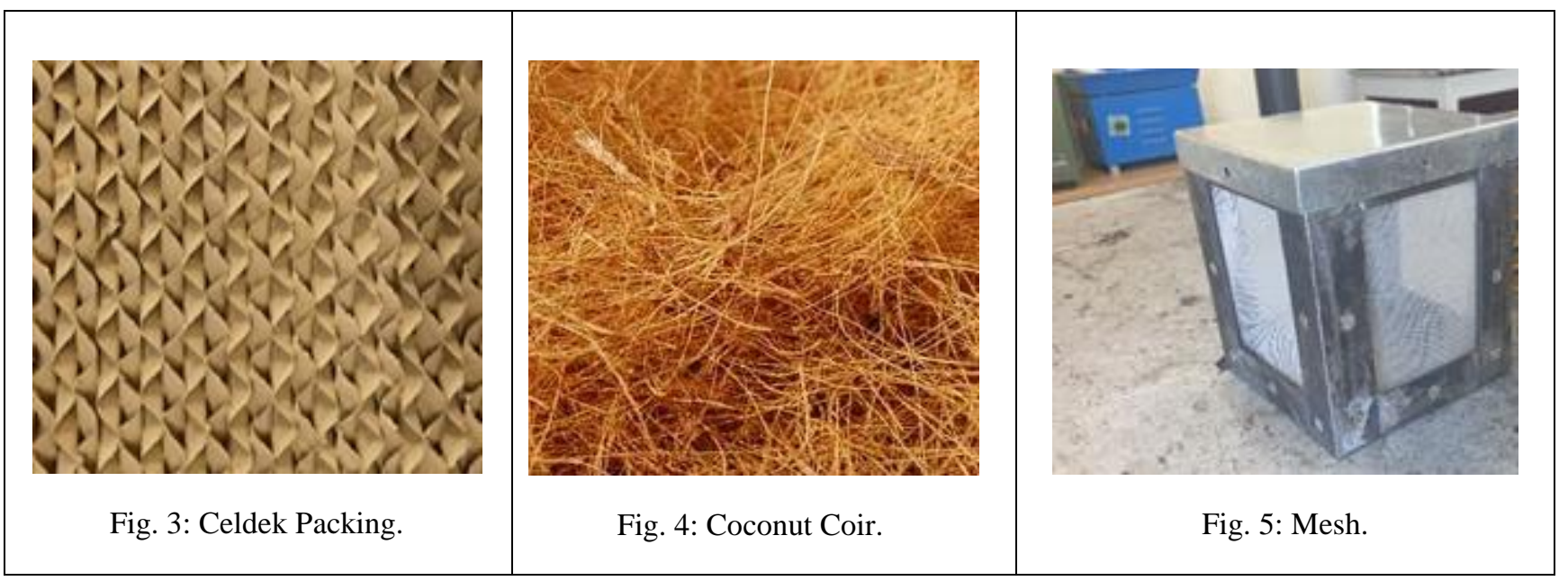

\section{Instruments Used For Testing:}

Table 1: Measuring devices to measure the parameters of humidification.

\begin{tabular}{|c|c|c|c|c|}
\hline Sl. No & $\begin{array}{c}\text { Type of } \\
\text { Instrument used }\end{array}$ & To measure & Specification & Accuracy \\
\hline 1. & $\begin{array}{c}\text { Thermometer (Dry } \\
\text { bulb temperature) }\end{array}$ & Temperature & $\begin{array}{c}\text { Temperature range: } \\
-20 \text { to } 100^{\circ} \mathrm{C} \\
\text { Probe Diameter } 6 \mathrm{~mm} \\
\text { Probe Material: Stainless steel } \\
\text { Resolution: } 0.1^{\circ} \mathrm{C}\end{array}$ & $\pm 0.1^{\circ} \mathrm{C}$ \\
\hline 2. & $\begin{array}{c}\text { Thermometer (Wet } \\
\text { bulb temperature) }\end{array}$ & Temperature & $\begin{array}{c}\text { Temperature range: } \\
-20 \text { to } 100^{\circ} \mathrm{C} \\
\text { Probe Diameter } 6 \mathrm{~mm} \\
\text { Probe Material: Stainless steel } \\
\text { Resolution: } 0.1^{\circ} \mathrm{C}\end{array}$ & $\pm 0.1^{\circ} \mathrm{C}$ \\
\hline 3. & Hygrometer & Humidity & $\begin{array}{c}\text { RH Range: } 0 \%-99 \% \\
\text { Power supply: } 1.5 \mathrm{~V} \\
\text { Display resolution: } 0.1 \%\end{array}$ & $\pm 2.0 \%$ \\
\hline 4. & Anemometer & Air Velocity & $\begin{array}{c}\text { Speed range: } 0-50 \mathrm{~m} / \mathrm{s} \\
\text { Threshold sensitivity: } 1 \mathrm{~m} / \mathrm{s} \\
\text { Resolution:0.05 } \mathrm{m} / \mathrm{s}\end{array}$ & $\pm 0.3 \mathrm{~m} / \mathrm{s}$ \\
& & & & \\
\hline
\end{tabular}




\section{Results And Discussion}

Experiments are carried out with the variation of air velocity, and water temperature. Inlet air is supplied by the and the Area of cross section at the inlet is $0.0225 \mathrm{~m}^{2}$ and Density of air of $1.225 \mathrm{~kg} / \mathrm{m}^{3}$ is considered. Using the output parameters like mass flow rate, heat transfer rate, cooling effect evaporation rate, humidification efficiency, coefficient of performance and Specific cooling capacity are determined. Figure. 6 shows the variation of the evaporation rate with the air velocity. Evaporation rate determines the amount of water that has evaporated from the pad surface with time. Graphical representation shows that with the rise in the air velocity, there is an increase in evaporation rate. Each curve is drawn with respect to the temperature of the water flowing into the packing. Evaporation rate for coconut coir all tested water temperatures are lesser than the respective temperatures for Celdek. For the highest velocity evaporation rate of Celdek packing is 4,5 and $4 \%$ higher than that of coconut coir packing. It is also found that evaporation rate for coconut coir at water temperature of $5^{\circ} \mathrm{C}$ is higher than that of the Celdek packing at water temperature of $10^{\circ} \mathrm{C}$. This indicates the temperature of water plays a vital role in the output humidification performance.

Figure.7 Shows the variation of coefficient of performance with the air velocity. Coefficient of performance is given by the ratio of the cooling effect to the work done. In the above system, work is done by blower, refrigeration unit and the circulation pump. There is a rise in the COP with the increase in the air velocity. Cooling effect increases with rise in air velocity because of high difference in the dry bulb temperature and the increased mass flow rate. For the lowest water temperature, the COP obtained is higher, because of higher cooling effect and increased change in DBT. Experimental results are considered for maximum air velocity and three different water temperatures, graphical conditions showed that the Celdek packing gave better coefficient performance than the coconut coir by $4,3 \& 4 \%$ for 5,10 and $15^{\circ} \mathrm{C}$ water temperatures. It may also be influenced by the material of the cooling pads. Wettability of Celdek Packing is higher than the coconut coir. This increases the amount of water exposed to air which increases the evaporation rate. Similarly, with the increase in the water temperature there is a drop in the COP.

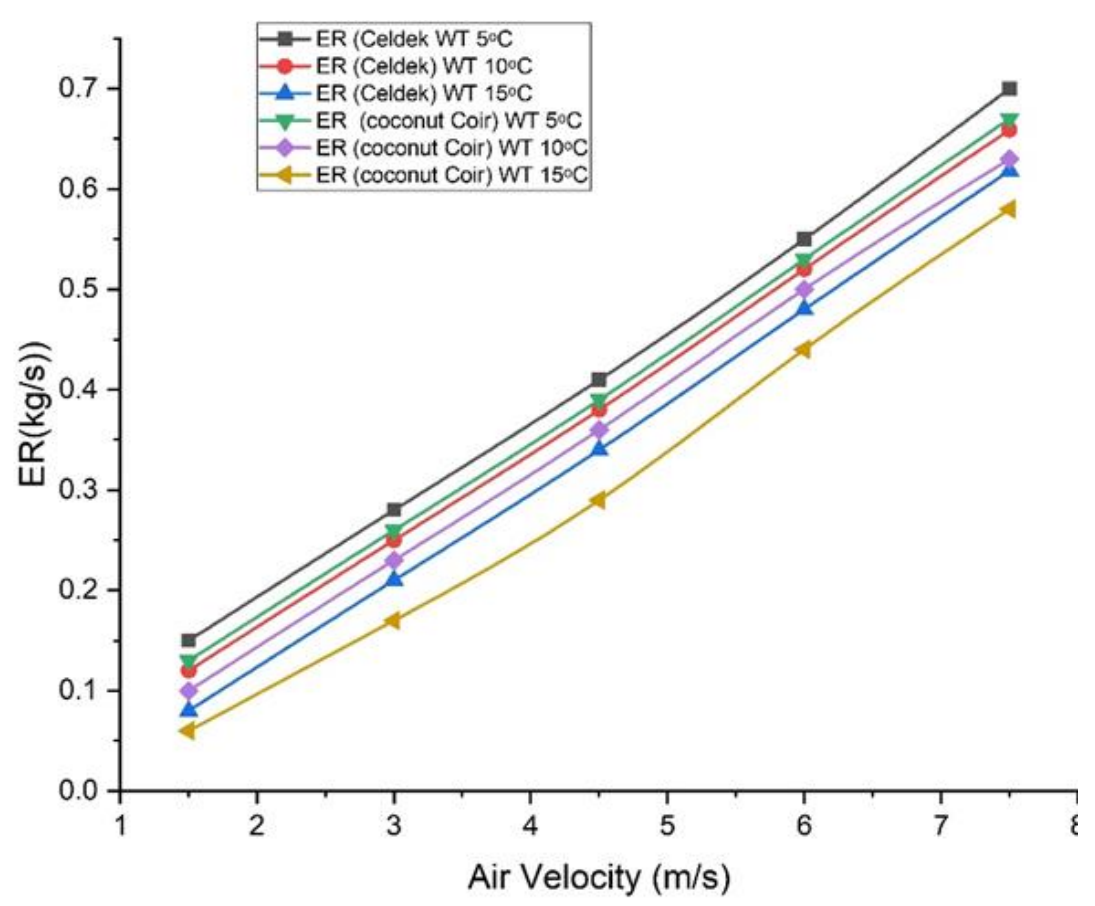

Fig. 6: Variation of evaporation rate with air velocity. 


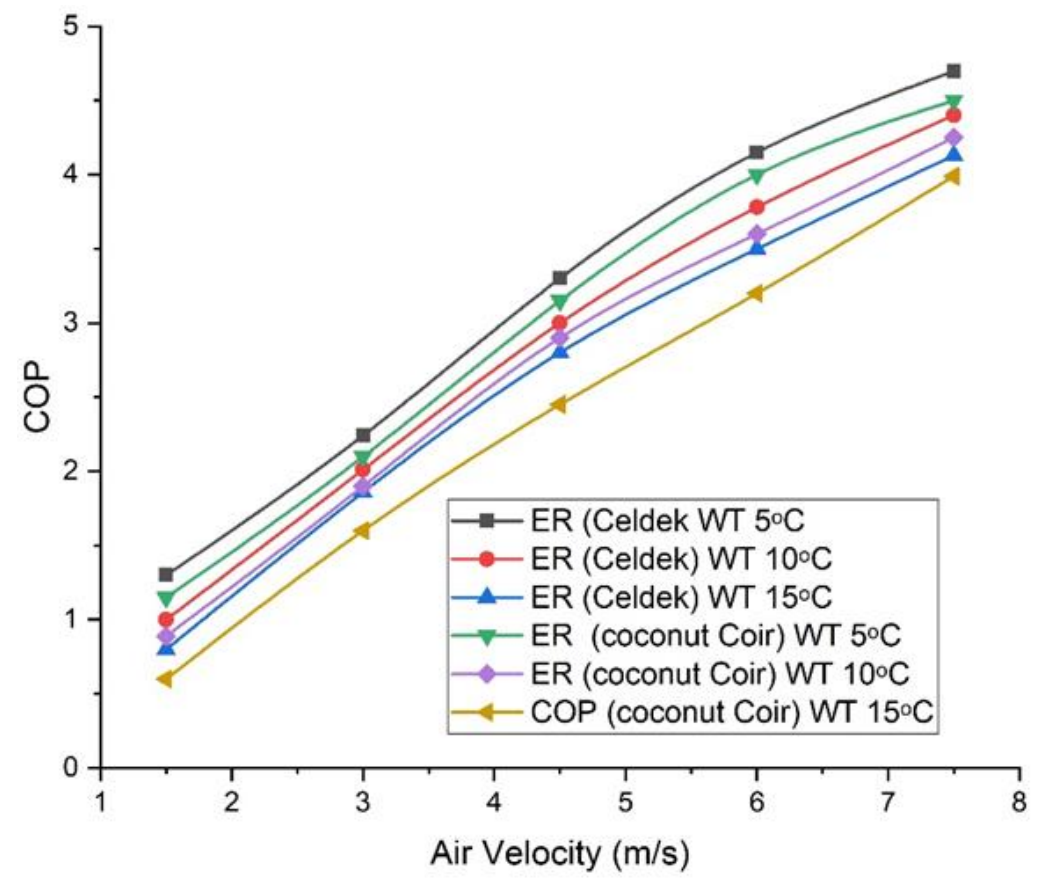

Fig. 7: Variation of COP with air velocity.

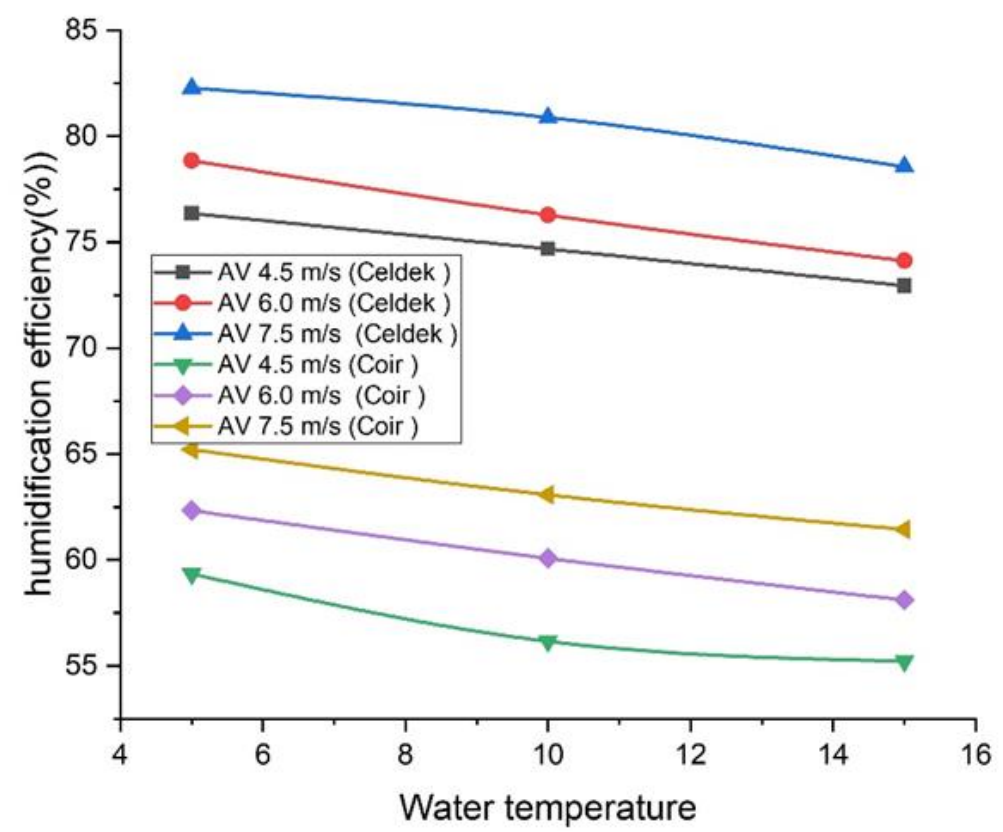

Fig. 8: Variation of Humidification efficiency with water temperature. 


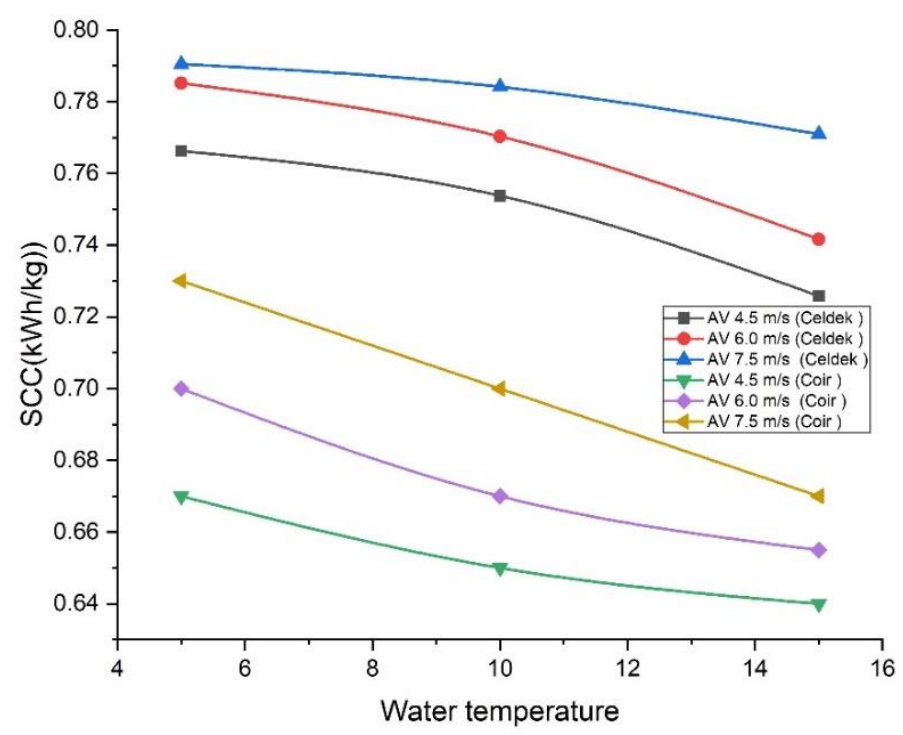

Fig. 9: Specific cooling capacity with water temperature.

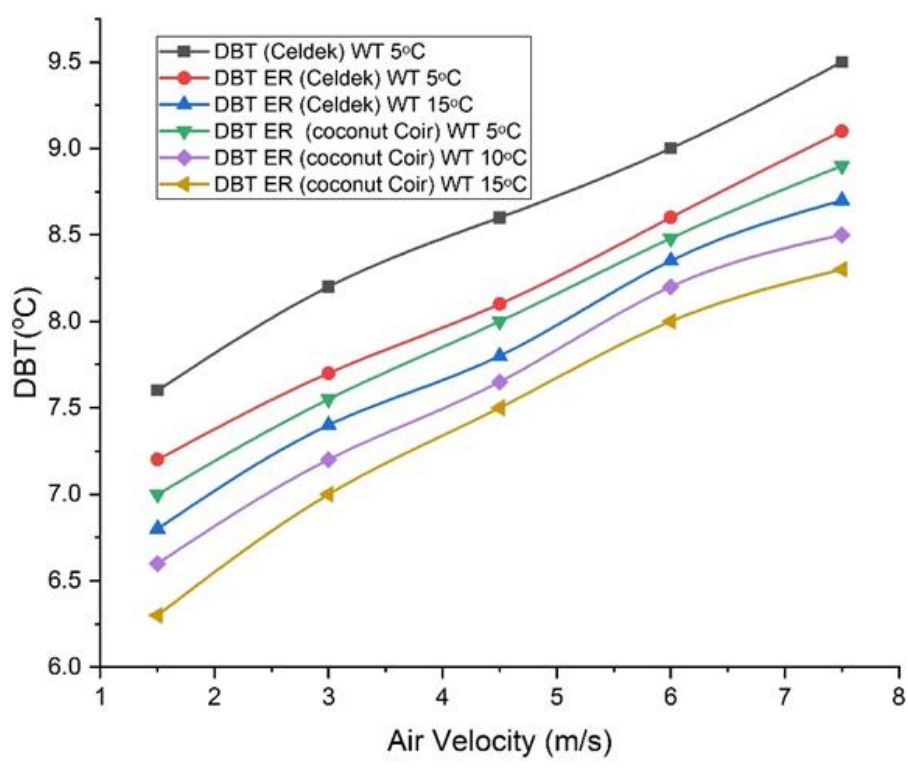

Fig. 10: Change in Dry bulb temperature with Air velocity.

Humidification efficiency variation with the water temperature is discussed in the figure.8. It is defined as the ratio of the temperature difference between the inlet and outlet DBT to the difference between the inlet and wet bulb temperature. With the increase in the temperature of the water there is a drop in the humidification efficiency. It is because the as the water temperature is lower DBT difference is larger. Large temperature difference indicate more heat lost by the air. This increase the humidification efficiencies at lower water temperatures. Celdek can absorb and hold higher water content during evaporation and exchanges more energy than coconut coir. Three different air velocities are considered, and it is seen that Celdek packing yield the humidification efficiency in the range 70 to $82 \%$ whereas Coconut coir gives the efficiency of 55 
to $65 \%$. For the lower water temperature and higher air velocity, the difference in percentage between the Celdek and coconut coir is $17 \%$.

Specific cooling capacity is defined as the ratio of the cooling effect to the evaporation rate. Figure. 9 shows the variation of the SCC with the water temperature. There is a significant drop observed in the SCC value as the water temperature is increased, on the other hand, it increased with the increase in air velocity. For lowest water temperature, Celdek packing gave a higher SCC value by $7.3 \%$. Celdek packing possess higher porosity, surface air, configuration, and absorbing capacity higher than coconut coir. Due to long extended and tubular structure, the porosity of coconut coir is less and hence the absorbing capacity is also lower. Due to this, for the definite amount of heat lost by the air, water evaporation rate is higher in coconut coir than Celdek packing. This gives lower SCC for coconut coir.

Figure. 10 shows the variation of dry bulb temperature with the air velocity. It is the difference between the inlet and outlet DBT values. It shows an increasing trend in the change in DBT with the increase in air velocity which means the cooling capacity will be higher as it receives more energy from air. Cellulose packing gave higher DBT drop than coconut coir because of good absorption and wettability property. Cellulose also exhibit properties like penetrability, absorbent and high energy acquiring from air during evaporation. Results indicate that for lower water temperature and higher air flow rate, Celdek packing showed $6.3 \%$ increase in the DBT compared to coconut coir.

\section{Validation}

Table 2: Comparison of present experimental results with literature values.

\begin{tabular}{|c|c|c|c|c|c|c|c|c|c|}
\hline $\begin{array}{l}\text { Sl. } \\
\text { No }\end{array}$ & Researcher & $\begin{array}{l}\text { System } \\
\text { type }\end{array}$ & $\begin{array}{l}\text { Operating } \\
\text { Conditions }\end{array}$ & $\begin{array}{l}\Delta \mathrm{DBT} \\
\left({ }^{\circ} \mathrm{C}\right)\end{array}$ & $\begin{array}{l}\text { Change in } \\
\text { relative } \\
\text { humidity } \\
(\%)\end{array}$ & $\begin{array}{l}\text { Humidifi } \\
\text { cation } \\
\text { efficienc } \\
\text { y }(\%)\end{array}$ & $\begin{array}{l}\mathrm{SCC} \\
(\mathrm{kW}- \\
\mathrm{hr} / \mathrm{kg})\end{array}$ & $\begin{array}{l}\text { Evaporatio } \\
\mathrm{n} \text { rate }(\mathrm{g} / \mathrm{s})\end{array}$ & $\Delta \mathrm{P}$ \\
\hline 1. & J K Jain [1] & $\begin{array}{l}\text { Alternate } \\
\text { cooling } \\
\text { pads }\end{array}$ & $\begin{array}{c}\text { Air velocity= } 1 . \text { to } \\
5 \mathrm{~m} / \mathrm{s} \\
\text { Water } \\
\text { temperature }= \\
\text { room temp. }\end{array}$ & 5.2 & 30 & 70 & 0.82 & 0.21 & 87 \\
\hline 2. & Malli, A [2] & $\begin{array}{l}\text { Celdek/Cel } \\
\text { lulose pads }\end{array}$ & $\begin{array}{c}\text { Air velocity= } 1.7 \\
\text { to } 4 \mathrm{~m} / \mathrm{s} \\
\text { Water } \\
\text { temperature }= \\
\text { room temp. }\end{array}$ & 5.4 & 33 & 64 & 0.91 & 0.22 & 84 \\
\hline 3. & $\begin{array}{c}\text { Nada, S.A } \\
\text { [3] }\end{array}$ & $\begin{array}{l}\text { Eucalyptus } \\
\text { cooling pad }\end{array}$ & $\begin{array}{l}\text { Air velocity=1.1 to } \\
2 \mathrm{~m} / \mathrm{s} \\
\text { Water temperature= } \\
\text { room temp. }\end{array}$ & 6.3 & 35 & 71 & 0.90 & 0.44 & 74 \\
\hline 4. & $\begin{array}{l}\text { Present } \\
\text { study }\end{array}$ & $\begin{array}{l}\text { Cellulose } \\
\text { Pads and } \\
\text { Coconut } \\
\text { Coir }\end{array}$ & $\begin{array}{c}\text { Air velocity }=1.5 \\
\text { to } 7.5 \mathrm{~m} / \mathrm{s} \text { Water } \\
\text { temperature }=5 \text { to } \\
15^{\circ} \mathrm{C}\end{array}$ & 9.5 & 35 & 82 & 0.8 & 0.7 & 98 \\
\hline
\end{tabular}

Table 2 shows the comparison of the output parameters obtained in the present literature with the existing literature. It is found that all the output parameters showed better results when compared to the different values put out in the published literature. Hence, the results obtained in the present work is validated.

\section{Conclusion:}

Performance of two types of cooling pads cellulose and coconut coir are experimentally investigated with respect to variation in air velocity, water temperature under crossflow conditions The performance parameters like change in DBT, COP, SCC \& humidification efficiency are determined. The following conclusions are drawn.1. Increase in the air velocity, 
rises the evaporation rate and coefficient of performance. Celdek packing exhibited higher performance values of $0.7 \mathrm{~g} / \mathrm{s}$ and 4.68 which is $4 \%$ and $5 \%$ higher compared to the coconut coir. 2.Lower water temperature yielded higher humidification efficiency and specific cooling capacity. System yielded efficiency of $82.27 \%$ and SCC value of $0.79 \mathrm{kw}-\mathrm{hr} / \mathrm{kg}$ which is higher than coconut fibers packing. Maximum change in DBT value obtained in the system is $9.5^{\circ} \mathrm{C}$ for Celdek packing. 3.Considering performance parameters among Celdek packing and coconut coir, Coconut coir results are closer to the Celdek values. Hence coir can be considered as an alternative pad material by considering the fact of easy availability, durable, economical, and easily given packing shapes.

\section{Nomenclature:}

\begin{tabular}{|l|l|}
\hline$\Delta \mathrm{T}=$ Change in temperature, ${ }^{\circ} \mathrm{C}$ & $\mathrm{M}_{\mathrm{w}}=$ Evaporation rate, $\mathrm{g} / \mathrm{s}$ \\
\hline $\mathrm{T}_{1 \mathrm{~d}}=$ Inlet DBT, ${ }^{\circ} \mathrm{C}$ & $\mathrm{M}_{\mathrm{a}}=$ Mass flow rate of air, $\mathrm{kg} / \mathrm{s}$ \\
\hline $\mathrm{T}_{2 \mathrm{~d}}=$ Outlet DBT, ${ }^{\circ} \mathrm{C}$ & $\mathrm{W}_{2}=$ Specific humidity outlet, ${ }^{\circ} \mathrm{C}$ \\
\hline $\mathrm{Tw}=$ Wet bulb temperature, ${ }^{\circ} \mathrm{C}$ & $\mathrm{W}_{1}=$ Specific humidity Inlet, ${ }^{\circ} \mathrm{C}$ \\
\hline$\eta_{\text {humididication}}=$ Humidification efficiency, $\%$ & $\mathrm{~h}_{1}$ and $\mathrm{h}_{2}=$ Enthalpies, $\mathrm{kJ} / \mathrm{kg}$ \\
\hline $\mathrm{COP}=$ Coefficient of performance & $\mathrm{SCC}=$ Specific cooling capacity, $\mathrm{kW}-\mathrm{hr} / \mathrm{kg}$ \\
\hline $\mathrm{DP}=$ Dew point temperature, ${ }^{\circ} \mathrm{C}$ & $\mathrm{RH}=$ Relative Humidity, $\%$ \\
\hline $\mathrm{W}_{\text {pump }}=$ Power in pump, Watts & $\mathrm{DB}=$ Dry bulb temperature, ${ }^{\circ} \mathrm{C}$ \\
\hline $\mathrm{W}_{\text {Blower }}=$ Power in blower, watts & $\mathrm{WB}=$ Wet Bub temperature, ${ }^{\circ} \mathrm{C}$ \\
\hline AT $=$ Air temperature, ${ }^{\circ} \mathrm{C}$ & $\mathrm{WT}=$ Water temperature, ${ }^{\circ} \mathrm{C}$ \\
\hline
\end{tabular}

\section{Acknowledgements}

Authors are thankful to the lab support provided by the School of Engineering \& IT, Manipal Academy of Higher education, Dubai, UAE.

\section{References}

[1] Jain, J.K. and Hindoliya, D.A., 2011. Experimental performance of new evaporative cooling pad materials. Sustainable Cities and Society, 1(4), pp.252-256.

[2] Malli, A., Seyf, H.R., Layeghi, M., Sharifian, S. and Behravesh, H., 2011. Investigating the performance of cellulosic evaporative cooling pads. Energy Conversion and Management, 52(7), pp.2598-2603.

[3] Nada, S.A., Fouda, A., Mahmoud, M.A. and Elattar, H.F., 2019. Experimental investigation of energy and exergy performance of a direct evaporative cooler using a new pad type. Energy and Buildings, 203, p.109449.

[4] Doğramacı, P.A., Riffat, S., Gan, G. and Aydın, D., 2019. Experimental study of the potential of eucalyptus fibres for evaporative cooling. Renewable Energy, 131, pp.250-260.

[5] Laknizi, A., Mahdaoui, M., Abdellah, A.B., Anoune, K., Bakhouya, M. and Ezbakhe, H., 2019. Performance analysis and optimal parameters of a direct evaporative pad cooling system under the climate conditions of Morocco. Case Studies in Thermal Engineering, 13, p.100362.

[6] Dhamneya, A.K., Rajput, S.P.S. and Singh, A., 2018. Thermodynamic performance analysis of direct evaporative cooling system for increased heat and mass transfer area. Ain Shams Engineering Journal, 9(4), pp.2951-2960. 
[7] Xu, Z., Xie, Y. and Xiao, Y., 2017. A compact packing humidifier for the micro humid air turbine cycle: Design method and experimental evaluation. Applied Thermal Engineering, 125, pp.727-734.

[8] Rafique, M.M., Gandhidasan, P., Rehman, S. and Al-Hadhrami, L.M., 2015. A review on desiccant based evaporative cooling systems. Renewable and Sustainable Energy Reviews, 45, pp.145-159.

[9] Camargo, J.R., Ebinuma, C.D. and Silveira, J.L., 2005. Experimental performance of a direct evaporative cooler operating during summer in a Brazilian city. International Journal of Refrigeration, 28(7), pp.1124-1132.

[10] Franco, A., Valera, D.L. and Peña, A., 2014. Energy efficiency in greenhouse evaporative cooling techniques: cooling boxes versus cellulose pads. Energies, 7(3), pp.1427-1447.

[11] Kabeel, A.E., Hamed, M.H., Omara, Z.M. and Sharshir, S.W., 2014. Experimental study of a humidificationdehumidification solar technique by natural and forced air circulation. Energy, 68, pp.218-228.

[12] Shahali, P., Rahmati, M., Alavi, S.R. and Sedaghat, A., 2016. Experimental study on improving operating conditions of wet cooling towers using various rib numbers of packing. International journal of refrigeration, 65, pp.80-91.

[13] Martínez, P., Ruiz, J., Martínez, P.J., Kaiser, A.S. and Lucas, M., 2018. Experimental study of the energy and exergy performance of a plastic mesh evaporative pad used in air conditioning applications. Applied Thermal Engineering, 138, pp.675-685.

[14] Liu, X., Guan, B. and Liu, X., 2015. Experimental study on the filtration efficiency of structured packing air handling processors. Procedia Engineering, 121, pp.2037-2043.

[15] Li, Y., Huang, X., Peng, H., Ling, X. and Tu, S., 2018. Simulation and optimization of humidification-dehumidification evaporation system. Energy, 145, pp.128-140.

[16] Warke, D.A. and Deshmukh, S.J., 2017. Experimental analysis of cellulose cooling pads used in evaporative coolers. Int. J. Energy Sci. Eng., 3(4), pp.37-43.

[17] Sharma, A., Kumar, M., Ranjan, R. and Krishnan, A.A., Conversion of dessert cooler into low cost air conditioner using Peltier module.

[18] Al-Sulaiman, F., 2002. Evaluation of the performance of local fibers in evaporative cooling. Energy conversion and management, 43(16), pp.2267-2273. 